I N F ORM A I K A

Jurnal Informatika, Manajemen dan Komputer, Vol. 11 No. 1, Mei 2019

eISSN : 2580-3042

pISSN : 1979-0694

\title{
METODE DIGITAL ANIMATION DALAM PEMBUATAN FILM ANIMASI 2D VECTOR DENGAN TEMA HARAPAN DAN DOA
}

\author{
Tri Yuliati \\ Sekolah Tinggi Teknologi dumai \\ J1. Utama Karya Bukit Batrem II, Dumai - Riau \\ e-mail :triyuliati00@gmail.com
}

\begin{abstract}
ABSTRAK
Film animasi $2 \mathrm{D}$ vector dengan tema harapan dan doa dengan menggunakan pemanfaatan desain graphic menggunakan teknik digital animation yaitu penggabungan antara gambar manual di atas tablet pen, dan ditransfer ke komputer kemudian di konversi menjadi gambar digital animation. Film animasi memiliki fungsi sebagai alat penghibur dan sebagai media pembelajaran untuk anak sehingga anak tidak merasa bosan dan belajar menjadi menyenangkan karena adanya unsur hiburan. Melalui media film animasi bisa dijadikan bisa diajarkan nilai dan norma keagamaan saat musibah terjadi maupun kehidupan sehari-hari. Pengingat agar selalu tetap bertawakal, berdoa dan berserah diri kepada penciptanya. Cerita dari film animasi ini megenai pembelajaran pada saat adanya musibah, anak-anak agar selalu ingat do'adoa yang bisa mereka terapkan dari pembelajaran yang mereka dapatkan di TPQ. Video Edutainment ini dapat digunakan oleh guru maupun orang tua untuk memberikan pelajaran atau mengubah perilaku dan karakter pada anak seperti karakter mengingat do'a pada setiap kehidupan sehari-hari.
\end{abstract}

Kata kunci : Film, Animasi, Vector

ABSTRACT

$2 D$ vector animated film with the theme of hope and prayer by using the graphic design utilization using digital animation technique, which is a combination of manual drawing on a tablet by pen then transferred to a computer and converted to digital animation. Animater film has aim to entertaining and learning media for children thues the children do not feel bored and have fun learning because the film has entertainment element. Animated film can be used to be taught religious values and norms during the disaster and daily life. As a reminder to always remain trustworthy, pray and submit to the creator. The story of this animated film is about learning in the event of a disaster, the children always remember to pray the dua from the learning which they get at TPQ. This Edutainment video can be used by teachers and parents to provide lessons or change behavior and character in children such as the character of remembering to pray in every day life.

Keywords : Film, Animasi, Vector

\section{PENDAHULUAN}

Industri film animasi di Indonesia saat ini mulai berkembang dan semakin banyak kemajuan dari tahun ke tahun sebelumnya yang mana film animasi pada stasiun Televisi Indonesia masih mengimpor dari negara lain. Hal ini berkaitan dengan besarnya investasi dan rutinitas sumber daya manusia (SDM) yang ada. Para animator Indonesia beranggapan bahwa industri film animasi membutuhkan biaya yang besar serta sumber daya manusia yang benarbenar menguasai dan memahami seluk beluk pembuatan film animasi yang dinilai rumit.
Namun dengan sistem komputerisasi sekarang ini, indonesia dapat memproduksi film animasi dengan murah dan cepat.

Indonesia belakangan ini sering mendapat musibah bencana alam. Mulai dari Tsunami Aceh 2004, Gempa Jogja 2006, Gunung Merapi 2010, Palu 2018 dan Tsunami Banten dan Lampung 2018 akhir. Banyak hal yang membuat psikologis anak-anak maupun orang dewasa yang terkena dampak bencana menjadi rapuh. Perlu pendekatan kepada para korban melalui terapi dan juga bantuan. Terlepas dari itu satu hal tidak 
I N F O R M A I I A

Jurnal Informatika, Manajemen dan Komputer, Vol. 11 No. 1, Mei 2019

eISSN : 2580-3042

pISSN : 1979-0694

boleh lupa adalah harapan dan doa untuk bisa bangkit dari keterpurukan.

Bencana alam merupakan bencana yang diakibatkan oleh peristiwa atau serangkaian peristiwa yang disebabkan oleh alam antara lain berupa gempa bumi, tsunami, gunung meletus, banjir, kekeringan, angin topan, dan tanah longsor dan lain-lain (Presiden Republik Indonesia, 2007)Badan Nasional Penanggulangan Bencana mengumpulkan tren kejadian bencana alam dalam 14 tahun terakhir di Indonesia seperti yang dirujuk pada gambar 1 .

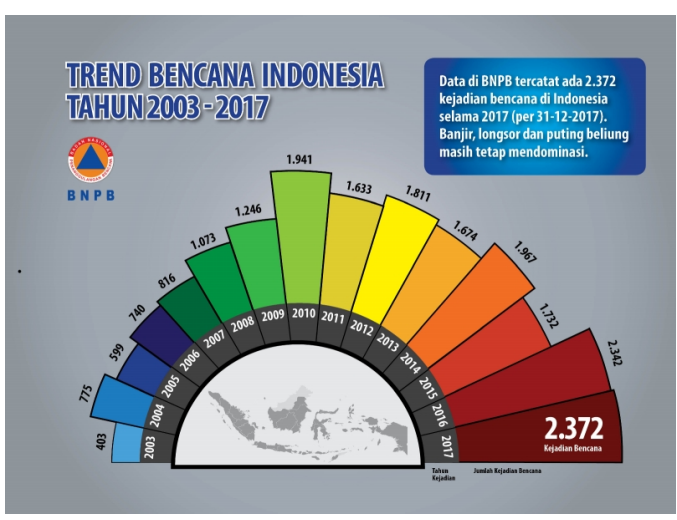

Gambar 1. (BNPB, 2019)

Banyak media yang bisa dijadikan alat sebagai pengingat manusia akan tuhannya. Pengingat agar selalu tetap bertawakal, berdoa dan berserah diri kepada penciptanya. Hal tersebut banyak dishare melalui pesan singkat, video dan di media sosial. Saat ini mulai banyak hadir media-media yang mengajak dan mengajarkan tentang nilai-nilai agama seperti menghafal doa sehari-hari disertai dengan contoh berperilaku yang baik. Media-media yang digunakan sangat beraneka ragam, ada yang melakukan pendekatan melalui komunikasi di bidang pendidikan, multimedia, trend busana sampai dengan musik.

Dampak psikologis pada anak-anak korban bencana yang dimaksud antara lain : (1) Kesedihan mendalam karena kehilangan kasih sayang keluarga bagi anak yang ditinggalkan. Hal ini membuat hilangnya semangat hidup. (2) Hilangnya harga diri dan kemampuan seorang anak karena di tempat pengungsian mereka menerima belas kasihan dari pihak lain dan bahkan seringkali menjadi tontonan. (Adi, Amawidyati, \& Utami, n.d.). Hal ini membuat dampak negatif dari peristiwa traumatis yang dialami akan menjadi lebih mudah diatasi dibandingkan seseorang yang tidak memiliki kepercayaan terhadap agama yang kuat.

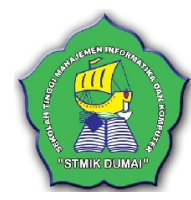

Religiusitas dalam menghadapi bencana perlu dibangun sejak usia dini. Anak usia dini pada rentang usia 3-5 tahun dapat ditanamkan nilai-nilai tersebut melalui PAUD (Pendidikan Anak Usia Dini). (Hastuti, 2015)

Penggunaan teknik rotoscope dalam produksi film animasi ini dikarenakan gagasan atau konsep yang ingin disampaikan dalam cerita mempunyai kesesuaian. Teknik ini juga mempunyai kelebihan efisiensi waktu produksi karena teknik ini merupakan teknik menjiplak gambar dari video aslinya. (Rahman, Suminto, \& Purwacandra, 2017).

Pembuatan aplikasi film animasi 2D dengan tema sedekah menggunakan teknik 2D Hybrid Animation dengan pemanfaatan Graphic yang mengandung nilai edutaiment untuk anakanak. Edutainment dapat digunakan oleh guru maupun orang tua untuk memberikan pelajaran atau mengubah perilaku dan karakter pada anak seperti karakter suka bersedekah. Film animasi ini diuji cobakan kepada orang tua, guru, dan anak-anak PAUD maupun TK. (Syafrudin \& Pujiyono, 2013)

(Rona G, Purnasiwi; Mei P, 2013)Dalam membuat sebuah animasi diperlakukan teknik khusus, agar animasi yang dihasilkan berkualitas. Teknik animasi tersebut diantaranya :

1. Stop Motion Animation

Animasi dibentuk dari gambar-gambar yang dibuat secara grafis yang kemudian digerakan. Jadi animasi stop motion adalah cara atau teknik yang bisa dipakai untuk menciptakan sebuah animasi. Peralatan yang dibutuhkan hanya kamera foto atau kamera video, tripod atau apapun yang dapat menyangga kamera tepat pada tempatnya, dan yang paling penting adalah obyeknya.

2. Hybrid Animation

Merupakan teknik membuat animasi dengan cara menggambar manual diatas kertas, kemudian ditransfer ke komputer.

3. Digital Animation

Merupakan teknik membuat animasi dengan murni menggambar di komputer. Peralatan yang digunakan sudah serba digital. Beberapa digital animation sebagai berikut :

a. Multi-Sketching

Merupakan sketsa gambar tangan menggunakan peralatan Pen-Tablet atau Digitalizer-Tablet yang di capture langsung menjadi video.

b. Cell-Shaded Animation

Cellshading atau Toonshading yaitu sebuah tipe dari non photo realistic rendering yang di desain untuk membuat grafik yang dibuat dari 
I N F ORM A I K A

Jurnal Informatika, Manajemen dan Komputer, Vol. 11 No. 1, Mei 2019

eISSN : 2580-3042

pISSN : 1979-0694

komputer terlihat seperti gambar oleh tangan.

c. Onion Skinning

Teknik dari 2D komputer grafis untuk membuat animasi kartun dengan mengedit movie untuk melihat beberapa frame dalam suatu tampilan. Dalam hal ini animator dapat memutuskan untuk membuat atau merubah sebuah gambar berdasarkan gambar sebelumnya.

d. Rotoscoping

Rotoscoping adalah teknik animasi dimana animator mengambil gerakan nyata suatu dari film, secara frame by frame, dan digunkan untuk film animasi. Awalnya pre-rekaman film live action, gambar yang di proyeksikan ke sebuah panel kaca yang bek dan digambar ulang oleh animator. Peralatan proyeksi ini disebut peralatan rotoscope, walaupun perangkat ini telah digantikan oleh computer dalam beberapa tahun terakhir dalam industry efek visual, istilah rotoscoping merujuk kepada teknik secara manual dalam piringan liveaction agar dapat dikomposisikan dalam background lain.

Berdasarkan uraian di atas maka penting dibuat sebuah media edutainment berupa film animasi 2D menggunakan after effect dengan tema Harapan dan Doa yang dapat membantu adanya penanaman karakter tentang nilai-nilai keagamaan yang tinggi dan bagaimana menerima cobaan musibah yang datang dengan doa yang diterapkan pada kehidupan sehari-hari.

\section{METODOLOGI PENELITIAN}

Penelitian ini dilaksanakan di labor STT Dumai dan pelaksanaanya di TPQ Nurul Huda Kota Dumai.

Animasi yang dibuat adalah 2D vector dengan motion graphic. Hal ini menjadikan tampilan animasi bagaikan potongan-potongan media visual berbasis waktu yang menggabungkan film dan desain grafis. Animasi ini dibentuk dari gabungan animasi 2D, tipografi, ilustrasi, dan musik latar belakang. Alat bantu pembuatan film animasi antara lain Adobe Premiere CS6 dan Adobe After Effect CS6. Tahapan utama siklus hidup pengembangan sistem terdiri dari beberapa tahapan yaitu Siklus hidup pengembangan sistem dapat dilihat pada Gambar 2. 
I N F O R M A T I A

Jurnal Informatika, Manajemen dan Komputer, Vol. 11 No. 1, Mei 2019

eISSN : 2580-3042

pISSN : 1979-0694

berbeda di satu videonya dan masing-masing mempunyai makna dan pelajaran.:

Scene 1:

Raka seoarang anak laki-laki yang hidup di pinggir pantai dan mempunyai kakak bernama suci, setiap sore mereka selalu bermain layanglayamg dipinggir panta, tapi pada saat itu keadaan menjadi petaka. Tsunami menerjang pemukiman warga. Raka dan suci berhasil selamat tapi nahas mereka terpisah dari orang tua mereka. Mereka berdoa dan berharap agar dipertemukan kembali. Sampai suatu hari mereka berkumpul kembali setelah sempat berpisah.

Scene 2:

Setelah magrib anak-anak mengaji di sebuah TPQ seperti biasa, saat itu mereka dikejutkan dengan suara petir yang kuat dan hujan yang sangat lebat. Sehingga lambat laun pemukiman mereka tergenang air dan longsor mulai datang. Mereka berdoa terus menerus agar terhindar dari musibah tersebut dan mencari tempat yang aman.

Scene 3:

Fania dan Rania harus kehilangan rumah mereka karena kebakaran hutan yang terus menyebar sampai pemukiman warga, orang tua mereka hanya bisa menyelamatkan baju yang saat itu mereka pakai. Orang tua mereka pasrah akan musibah yang telah terjadi.

Proses pembuatan karakter menggunakan teknik Multi-Sketching pada tablet pen kemudian dirapikan menggunakan direct selection dan dilakukan pewarnaan di adobe illustrator proses pembuatan karakter terlihat pada gambar 4.

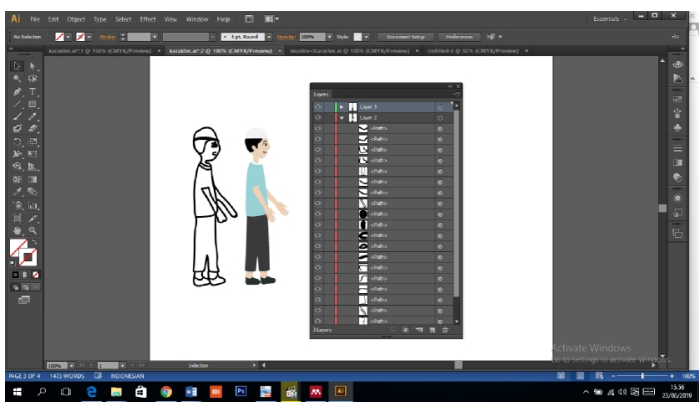

Gambar 4. Pembuatan karakter

Teknik onion skining menggunakan frame by frame $\mathrm{di}$ adobe after effect dengan menggunakan motion yang mudah yaitu position dan rotation dari karakter di adobe ilustrator yang diimport dengan pilihan composition seperti pada gambar 5 .

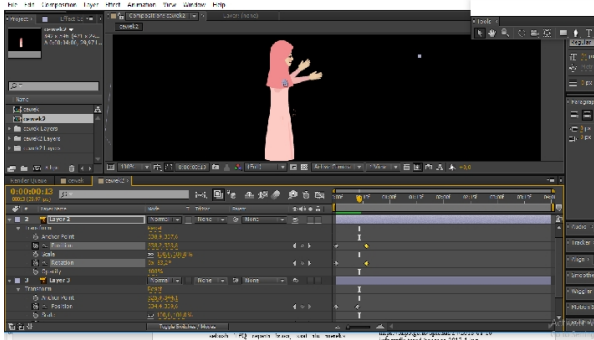

Gambar 5. Motion karakter

Hasil tampilan scene yang telah dihasilkan pada scene 1 cerita mengenai tsunami pada gambar 6 .

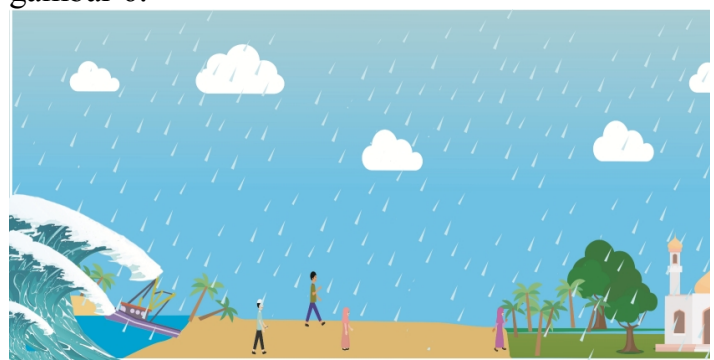

Gambar 6. Scene 1

Untuk hasil scene 3 mengenai kebakaran hutan dengan motion karakter pada gambar 5 . Dapat dilihat pada gambar 7 .

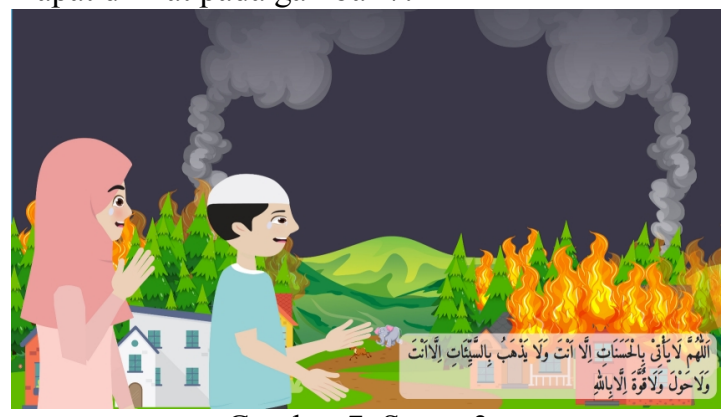

Gambar 7. Scene 3

Hasil pengujian di TPQ Nurul Huda yaitu dengan langsung melakukan pemutaran video dan berinteraksi dengan anak-anak, dapat dilihat pada gambar 8 .

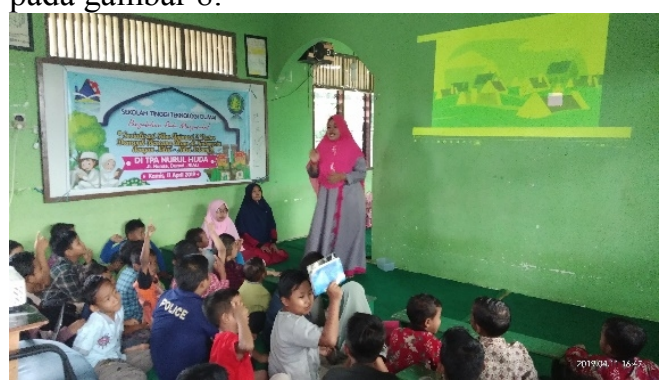

Gambar 8. Penyampaian Materi dan Pemutaran Film 
I N F O R M A I K A

Jurnal Informatika, Manajemen dan Komputer, Vol. 11 No. 1, Mei 2019

eISSN : $2580-3042$

\section{pISSN : $1979-0694$}

Selain memutar video berupa edutainment buat anak-anak, dilakukan sesi tanya jawab berupa hafalan doa-doa seputar scene yang telah diputar dan membuat anak-anak aktif dan menceritakan kejadian yang mereka alami dikehidupan sehari-hari disesi tanya jawab ini yang dapat dilihat pada gambar 9 .

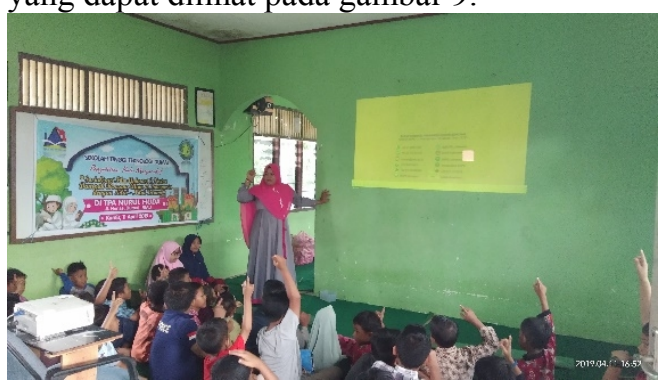

Gambar 9. Sesi Diskusi dan Tanya Jawab

\section{KESIMPULAN}

Hasil video berisi 3 pesan cerita mengenai 3 bencana yaitu tsunami, banjir dan kebakaran hutan. Tampilan berupa vector $2 D$ menggunakan teknik digital animation menggunakan bantuan pen tablet mampu mengilustrasikan cerita dari scene yang dibuat sehingga anak-anak TPQ Nurul Huda mampu mengenal dan mengingat kembali do'a-doa yang telah mereka pelajari, sehingga pemutaran video bisa mengilustrasikan kejadian-kejadian yang sebelumnya pernah mereka lihat baik di televisi maupun dimedia lainnya. Selain menghibur, pemutaran ini mampu menguji hafalan do'a-do'a yang telah mereka pelajari selama di TPQ.

\section{REFERENSI}

Adi, S., Amawidyati, G., \& Utami, M. S. (N.D.). Religiusitas Dan Psychological Well Being Pada Korban Gempa. 34(2), 164 176.

Bnpb. (2019). 2018-01-16-Infografis-TrendBencana-2017-1. Retrieved June 23, 2019 , From Bnpb Website: Https://Bnpb.Go.Id/Uploads/24/2018-0116-Infografis-Trend-Bencana-2017-1.Jpg

Hastuti, D. (2015). Penanaman Nilai-Nilai Agama Pada Anak Usia Dini Di Ra Tahfidz Al-Qur'an Jamilurrahman Banguntapan Bantul.

Presiden Republik Indonesia. Uu Ri No 24 Tentang Penanggulangan Bencana. (2007).

Rahman, F., Suminto, M., \& Purwacandra, P. P. (2017). Animasi Dua Dimensi Dengan
Teknik Rotoscope. 3(2). Retrieved From Http://Journal.Isi.Ac.Id/Index.Php/Jags/Arti cle/Download/1859/Fulltext

Rona G, Purnasiwi; Mei P, K. (2013). Peracangan Dan Pembuatan Animasu 2d “ Kerusakan Lingkungan” Dengan Teknik Masking. Journal Ilmiah Dasi, 14(04), 54$57 . \quad$ Retrieved From Https:/Media.Neliti.Com/Media/Publicatio ns/90062-Id-Perancangan-Dan-PembuatanAnimasi-2d-Ker.Pdf

Syafrudin, C., \& Pujiyono, W. (2013). Pembuatan Film Animasi Pendek "Dahsyatnya Sedekah" Berbasis Multimedia Menggunakan Teknik 2d Hybrid Animation Dengan Pemanfaatan Graphic. Jurnal Sarjana Teknik Informatika. 